\title{
A INFLUÊNCIA DA COMUNICAÇÃO NA PRODUTIVIDADE DAS ORGANIZAÇÕES
}

\author{
Geisiane Françosa Nogueira ${ }^{1}$ \\ João Marcos Codato
}

NOGUEIRA, G. F.; CODATO, J. M. A influência da comunicação na produtividade das organizações. Rev. Ciênc. Empres. UNIPAR, Umuarama, v. 20, n. 1, p. 63-81, jan./jun. 2019.

RESUMO: O presente trabalho teve como objetivo demonstrar como a comunicação pode influenciar a produtividade nas organizações, pesquisando acerca do tema comunicação e produtividade. Para tanto, a metodologia utilizada se caracteriza como estudo de natureza qualitativa e ainda pode ser classificada como exploratória. Os dados foram obtidos por meio do levantamento bibliográfico, com a utilização de livros e artigos. A pesquisa teve como hipóteses: a falha na comunicação influencia na satisfação dos colaboradores, gerando baixa produtividade e desempenho em suas tarefas; e ainda induz ao erro nas atividades a serem desempenhadas. Como conclusão, as hipóteses foram confirmadas, sendo que um processo de comunicação interna falho e a inexistência da cultura do diálogo tornam um ambiente insatisfatório para se trabalhar. Pelas informações serem ineficientes, os colaboradores não desempenham bem suas tarefas, diminuindo a produtividade e a satisfação, o que ameaça o andamento da empresa. Por outro lado, um processo de comunicação estratégico gera integração entre os colaboradores, melhora o fluxo de informações e estimula a obtenção de bons resultados, já que a comunicação está ligada aos propósitos da empresa e à sua força produtiva.

PALAVRAS-CHAVE: Comunicação; Produtividade; Satisfação.

\section{THE INFLUENCE OF COMMUNICATION IN ORGANIZATION PRODUCTIVITY}

\begin{abstract}
This paper has the purpose of studying how communication can influence productivity in the organizations, researching on communication and productivity topics. It used a methodology characterized as a qualitative

DOI: $10.25110 /$ receu.v20i1.6978

${ }^{1}$ Graduada em Análise e Desenvolvimento de Sistemas pela UNIPAR e pós-graduanda em MBA em Coaching e Liderança para a Gestão de Pessoas pela UNIPAR.

${ }^{2}$ Administrador pela UNIPAR, especialista em Controladoria e Gestão Financeira pela UNIPAR, especialista em Administração Hospitalar pela Universidade de Ribeirão Preto e Mestre em Desenvolvimento Regional e Agronegócio pela UNIOESTE.
\end{abstract}


study, which can also be classified as exploratory. The data were obtained through a literature review, using books and articles. The research was based on the hypotheses of how communication failure can influence the satisfaction of employees, generating low productivity and performance in their tasks, thus inducing errors in activities being performed. It could be concluded that when internal communication fail, and the dialogue culture is unsatisfactory at work, the hypothesis is verified. Since the information is inefficient, employees do not perform well, reducing productivity and satisfaction, which threatens the company's progress. On the other hand, a strategic communication process generates the integration of employees, improves the flow of information and encourages the achievement of good results, since communication is linked to the purposes of the company and its productive force.

KEY WORDS: Communication; Productivity; Satisfaction.

\section{LA INFLUENCIA DE LA COMUNICACIÓN EN LA PRODUCTIVIDAD DE LAS ORGANIZACIONES}

RESUMEN: El presente trabajo tuvo como objetivo demostrar cómo la comunicación puede influenciar la productividad en las organizaciones, investigando acerca del tema comunicación y productividad. Para ello, la metodología utilizada se caracteriza como estudio de naturaleza cualitativa y aún puede ser clasificada como exploratoria. Los datos fueron obtenidos a través del levantamiento bibliográfico, con la utilización de libros y artículos. La investigación tuvo como hipótesis: la falla en la comunicación influye en la satisfacción de los colaboradores, generando baja productividad y desempeño en sus tareas; y aún induce al error en las actividades a ser desempeñadas. Como conclusión, las hipótesis fueron confirmadas, siendo que un proceso de comunicación interna fallido y la inexistencia de la cultura del diálogo hacen un ambiente insatisfactorio para trabajar. Por las informaciones ineficientes, los colaboradores no desempeñan bien sus tareas, reduciendo productividad y la satisfacción, lo que amenaza el progreso de la empresa. Por otro lado, un proceso de comunicación estratégico genera integración entre los colaboradores, mejora el flujo de informaciones y estimula la obtención de buenos resultados, ya que la comunicación está vinculada a los propósitos de la empresa y su fuerza productiva.

PALABRAS CLAVE: Comunicación; Productividad; Satisfacción. 


\section{INTRODUÇÃO}

Com os avanços tecnológicos e a globalização, torna-se imprescindível que as empresas melhorem seus processos para continuarem competitivas, e a análise da comunicação e sua influência na produtividade, demonstra grande importância para essa melhoria nos processos e desenvolvimento das organizações, refletindo isso para seus clientes.

A pesquisa pretende demonstrar como a comunicação pode influenciar a produtividade nas organizações. Tendo em vista que a comunicação pode afetar os resultados de forma positiva, como satisfação, integração da equipe e qualidade na produção ou negativa, como insatisfação, retrabalho, improdutividade e rotatividade de pessoal.

A falha no processo de comunicação e a falta de abertura para o diálogo pode influenciar na satisfação dos colaboradores em relação as suas atividades e à empresa, além de ocasionar um baixo desempenho nas tarefas, diminuindo a produtividade. Por sua vez, a organização que possui uma força produtiva deficiente não consegue ter competitividade e nem se mantém no mercado.

A comunicação está relacionada com os objetivos da empresa e sua capacidade de produção, sendo que falhas podem prejudicar seu funcionamento. Dessa forma, torna-se relevante um estudo sobre o tema comunicação e produtividade, pois permite entender como ocorre essa influência no meio organizacional, possibilitando um posicionamento das empresas perante essa situação.

A pesquisa sobre comunicação e produtividade é significativa para as organizações e para a sociedade como um todo, pois permite analisar a importância da comunicação e desenvolvê-la, tanto as empresas, para melhorar seus processos, quanto para todas as pessoas, que devem melhorar essa competência para continuar no mercado de trabalho e se desenvolver no âmbito profissional e pessoal, podendo ser utilizados programas de desenvolvimento, como o coaching.

Este trabalho justifica-se para obtenção de experiência na vida acadêmica na área de gestão, além da possibilidade de desenvolver melhorias tanto para as empresas, quanto para as pessoas que nela trabalham. Portanto, este trabalho tem como objetivo geral demonstrar como a comunicação pode influenciar a produtividade nas organizações e como objetivos específicos, esclarecer o que é comunicação, definir o que é produtividade, analisar o processo de comunicação interna nas organizações e investigar como a comunicação afeta a produtividade.

Para tanto, a pesquisa consistiu em uma revisão bibliográfica sobre o tema comunicação e produtividade. É uma pesquisa do tipo exploratória e utiliza os procedimentos técnicos bibliográficos. A pesquisa investiga e analisa o assunto por meio da visão de outros autores, pois de acordo com Prodanov e Freitas 
(2013), as pesquisas exploratórias proporcionam informações sobre o tema, assumem a forma de pesquisas bibliográficas e permitem o estudo por diversos aspectos. Seguindo essa metodologia, será possível explorar o tema e conhecer os fatos relacionados.

A pesquisa possui natureza qualitativa, pois serão compreendidas as informações e explicada a relação de causa e efeito da comunicação na produtividade, que, de acordo com Bauer e Gaskell (2002), a pesquisa qualitativa cuida da interpretação das realidades. Dessa forma, serão entendidos e descritos os fatos do impacto da comunicação na produtividade das organizações, interpretando essa realidade.

Portanto, trata-se de uma pesquisa exploratória, permitindo a investigação sobre o tema por meio do levantamento bibliográfico em livros e artigos da área, observando os problemas do ponto de vista de diversos autores e interpretando as informações obtidas de forma qualitativa, possibilitando conhecer a realidade do problema.

\section{DESENVOLVIMENTO}

\subsection{O que é comunicação?}

A comunicação possui um papel importante nas relações humanas e na organização social, pois é um processo de interação social com a participação de pelo menos duas pessoas, com objetivo de transmitir mensagens e, eventualmente, recebê-las, através de um meio, visando o entendimento entre os envolvidos.

Comunicar é uma das necessidades básicas, pois é um ato de transferir informações. Segundo Stepanski e Costa (2012), a palavra comunicação vem do latim communis e significa tornar comum, pertencer a todos. Portanto, entende-se que a comunicação só é efetivada se todos os envolvidos compreenderam a mensagem.

A troca de informações consiste no entendimento entre as pessoas e, de acordo com Rosa e Landim (2009), quem transmite a informação deve saber se a mesma foi compreendida por quem a recebeu, pois a comunicação é a troca de entendimento, considerando as emoções e a situação que se transmite a mensagem. Assim, a comunicação torna as mensagens comuns e com significados.

Através da comunicação formam-se as estruturas sociais e as organizações, pois compartilham das mesmas idéias e objetivos. Segundo Chiavenato (2003), a comunicação é a troca de informações, tornando uma mensagem comum. Dessa forma, influencia no comportamento e na organização dos sistemas sociais, que devem se relacionar com o mesmo entendimento nas mensagens transmitidas e recebidas. Porém, se a informação transmitida não é compreendida, poderá gerar desentendimentos e desavenças nessas organizações. 
Interagir e se comunicar é um processo social que possui elementos e conforme Zimerman (1993), esse processo ocorre basicamente por um emissor, que emite uma mensagem; a mensagem, que é o conteúdo que deve ser emitido, uma estrutura de sinais verbal ou não-verbal, devendo ser formulada claramente; o canal, que é o meio onde se transmite a mensagem e o receptor, que recebe a mensagem.

$\mathrm{O}$ ato de se comunicar pode ocorrer verbalmente, por gestos, pelo corpo ou escrita. A comunicação verbal transmite informações de forma oral, pela linguagem falada, através de sons e palavras. Segundo Dancini (2012), para ser ter uma boa comunicação verbal, não depende de uma voz agradável, mas das mensagens claras e objetivas que devem ser passadas, sem precisar de um vocabulário rico, com a finalidade de nos fazer entender pelos demais.

Já a comunicação feita através dos gestos é uma forma de comunicação não verbal. As gesticulações podem ser utilizadas juntamente com a linguagem verbal, porém ambas devem estar em sintonia com o que está sendo transmitido, para não falar uma coisa e os gestos transmitirem outra.

Os gestos geralmente são feitos com as mãos e podem ser realizados inconscientemente em uma comunicação. São exemplos de gestos, segundo Weil e Tompakow (1986), virar as palmas das mãos para cima ou para baixo, apontar algo, levantar o polegar, demonstrar um formato de objeto com as mãos, entre outros.

A linguagem corporal é outra forma de comunicação não verbal, que ocorre pelo olhar, pela postura e pelas expressões faciais. A comunicação corporal transmite muitas informações e, caso esteja em discrepância com a linguagem verbal, ou seja, com as palavras que são transmitidas, a comunicação estará incompleta.

A mensagem deve ser transmitida de forma global e, de acordo com Dancini (2012), com o corpo e as palavras sendo compreendidos, além de que no processo de comunicação as expressões possuem uma proporção maior de impacto no receptor. Segundo Weil e Tompakow (1986), o corpo transmite angústia, cansaço, timidez, tensão, ansiedade, interesse, entre outros, de acordo com os movimentos e sinais que são realizados.

Outro tipo de comunicação muito importante para a transmissão de informações é a comunicação escrita, seja por e-mail, carta, bilhete, entre outros, com objetivo de passar um comunicado, delegar tarefas ou explicar as mesmas, porém o grande desafio é tornar as ideias em texto.

A comunicação escrita deve passar entendimento ao destinatário, mas segundo Dancini (2012, p. 96), “[...] é relativamente comum o erro de imaginar que, após a transmissão de informações (escritas, por exemplo), houve total entendimento e, portanto, a reação será a esperada [...]". Assim, se faz necessário 
checar as ideias que deseja transmitir na informação escrita e o grau de entendimento, além de verificar se o receptor da mensagem a interpretou e compreendeu de forma correta.

Portanto, o processo de comunicação deve estar em conformidade, sendo realizado de forma completa para que todos os envolvidos compreendam a informação transmitida, tornando as ideias em comum, com pleno entendimento, seja a mensagem disseminada de forma oral, escrita, por gestos ou pelo corpo.

\subsection{O processo de comunicação interna nas organizações}

Com a globalização e a competitividade no mercado, o público interno adquiriu um importante papel nos negócios, pois é por meio desse público que as práticas de produção e as tomadas de decisões são assimiladas, garantindo maior competitividade, qualidade e resultados para a organização.

A comunicação interna consiste em transferir informações aos colaboradores da organização e segundo Lima et al. (2012), é a comunicação destinada ao público interno. Deve-se determinar como levar essas mensagens às pessoas que trabalham na empresa, tornando um processo de comunicação interna efetivo.

Uma estratégia que deve ser vista nas organizações é a comunicação interna, pois um sistema de comunicação de qualidade reflete em resultados positivos para a empresa. De acordo com Lima et al. (2012), os colaboradores devem conhecer os objetivos, a missão, a visão, os valores, as decisões que são tomadas e o planejamento para o alcance das metas da organização. Dessa forma, os funcionários estarão integrados com a empresa e se sentirão responsáveis pelo sucesso dela.

Deve-se organizar a comunicação interna para garantir a máxima integração dos colaboradores com a empresa e, sobre isso, Matos (2014), afirma que é muito importante que todos os escalões conheçam os planos da organização, o que ela espera para os próximos períodos e o papel de cada um. Assim, os funcionários tendem a engajar-se, produzem mais e com melhor qualidade para atingir a meta da organização, pois sabem sua responsabilidade para o alcance dos objetivos e para com a empresa, além de consolidar sua imagem institucional.

São várias as redes de comunicação que podem ser utilizadas para a comunicação interna, ou seja, os canais que a informação circula. Os canais de comunicação podem ser formais, que é realizada por meio da hierarquia da organização, são os meios oficiais para o envio de informações e informais, que é realizada fora dos canais oficiais da empresa, como conversa no corredor, pausa para o almoço, entre outros, que interpretam os anúncios formais, podendo ocasionar boatos.

Na comunicação interna, pode ser utilizados veículos de informação, 
atingindo todos os colaboradores, mas com linguagem acessível para cada escalão, tornando comum a mensagem para todos. De acordo com Bahia (1995), as formas de comunicação interna são jornais, revistas, vídeos, boletins informativos, entre outros. Desse modo, as mensagens podem passar por diversos canais dentro de uma organização.

Com o avanço da tecnologia, também pode ser utilizado suas ferramentas como um veículo de informação e, sobre isso, Bahia (1995), concorda que a organização deve utilizar as tecnologias para se comunicar, cumprir metas, integrar e modernizar a empresa. Dessa forma, as tecnologias da informação podem ser utilizadas para a comunicação com o público interno.

Um estudo realizado pela Associação Brasileira de Comunicação Empresarial (ABERJE), em 2012, mostra que os principais veículos de comunicação interna são o comunicado por e-mail e a intranet. A pesquisa ainda mostra uma grande variedade de veículos utilizados para a comunicação, porém cada vez mais ganha espaço a comunicação digital, por alcançar um número grande de colaboradores, possuir maior velocidade, facilidade, baixo custo, entre outros.

$\mathrm{O}$ estudo considerou os segmentos das empresas participantes da pesquisa e avaliou que muitos funcionários, principalmente no segmento de indústrias, não têm acesso à comunicação digital, o que também caracteriza o negócio, apesar do crescimento da utilização dos veículos digitais pelas organizações.

Diante desse cenário, Matos (2014), discorda sobre o uso da tecnologia para a comunicação, pois quando substitui o contato entre as pessoas, torna uma relação entre máquinas e a comunicação é uma interação humana direta. Além da possibilidade do não entendimento das mensagens transmitidas, pois não há uma interação e nem um retorno efetivo na comunicação.

Por existir várias formas de se comunicar dentro da organização, Chiavenato (2003), afirma que os autores humanistas pesquisaram as redes de comunicação, objetivando encontrar a melhor maneira de se comunicar e obteve a conclusão que não existe uma única melhor forma de comunicar na empresa, porque há diversas situações e propósitos em que as informações são transmitidas pelas pessoas. Assim, conclui-se que a rede de comunicação ajuda a encontrar a forma mais indicada de se comunicar para cada situação. Portanto, a melhor maneira de se comunicar depende da situação.

O processo completo de comunicação dá-se por elementos que, segundo Matos (2014), são: emissor, aquele que emite uma mensagem; codificação, que codifica a mensagem transmitida, transformando-a em linguagem e adequando-a ao canal; mensagem é a estrutura organizada de sinais verbal ou não-verbal que será transmitida; canal é o meio em que se veicula a mensagem já codificada pelo emissor até chegar ao receptor; decodificação é a interpretação da mensagem pelo receptor, de acordo com a linguagem ou código utilizado; receptor é aque- 
le que recebe a mensagem e a decodifica, recuperando-a; feedback é o retorno da mensagem, permitindo a realimentação da comunicação e a continuidade do fluxo de mensagens, é a reação do receptor perante a mensagem que lhe foi transmitida; ruído é um sinal ou uma perturbação indesejável na transmissão de uma mensagem por um canal, dificulta a recepção e a compreensão da mensagem. Um exemplo que ilustra como ocorre o processo de comunicação pode ser visto na figura 1 .

Figura 1: Processo de Comunicação

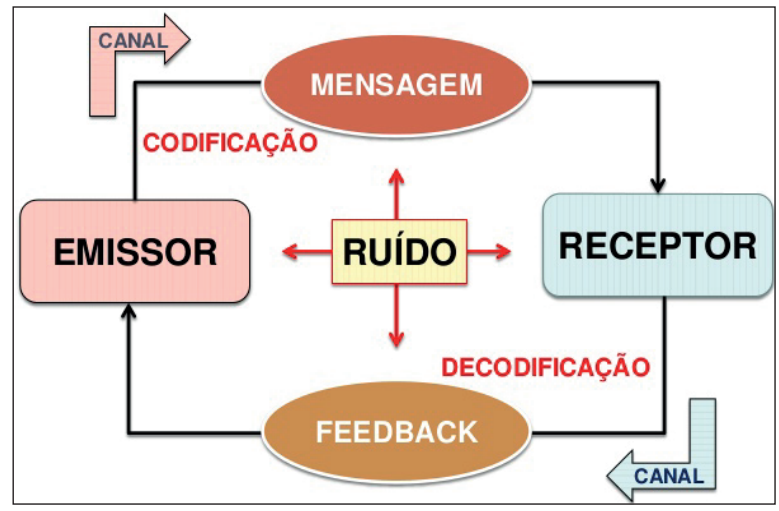

Fonte: Adaptado de Rocha, 2014)

No entanto, existem barreiras para se obter uma boa comunicação e, segundo Chiavenato (2009), essas barreiras são: pessoais, que representam as limitações de cada indivíduo, sendo que no âmbito organizacional ocorre pela falta de ouvir, pelas emoções, motivações e sentimentos de cada pessoa. Físicas, são as interferências que ocorrem no ambiente onde está acontecendo a comunicação, como ruídos, distância, entre outros. Semânticas, são as distorções dos símbolos pelo qual a comunicação é realizada, como palavras, gestos e outros sinais, que podem possuir significados diferentes para os indivíduos envolvidos no processo de comunicação. Além dessas barreiras, o autor inclui três males que podem existir na comunicação: omissão, quando partes importantes são omitidas da comunicação, fazendo com que a mesma não seja completa; distorção, quando a informação é alterada, afetando seu significado original; e sobrecarga, quando a quantidade de informações é grande e o destinatário não consegue processá-las, ocorrendo a perda de partes ou distorção. Todos esses obstáculos interferem na comunicação, porém podem ser minimizados pelos envolvidos.

É certo que a comunicação interna é muito falha nas organizações e Chiavenato (2003, p. 129), afirma que "as organizações estão longe de utilizar 
bem as comunicações". Em consequência, são geradas muitas falhas nas tomadas de decisão, na qualidade da produção, na competitividade e produtividade das organizações. Assim, verifica-se a necessidade de um processo de comunicação interna estratégico, para manter os colaboradores informados dos objetivos da empresa e engajados no alcance das metas.

\subsection{0 que é produtividade?}

A produtividade provavelmente evoluiu juntamente com o homem, que, segundo Pechincha (2010), utilizava o próprio corpo ou utensílios primitivos para caçar, sendo que ao longo do tempo, desenvolveu e melhorou as ferramentas e os processos produtivos, até chegar ao homem moderno, sempre preocupado em aumentar a produção.

Diante dessa evolução, estão os conceitos de produção e produtividade, cujo termos são diferentes, a produção consiste em criar valor, como bens e serviços, por meio dos fatores produtivos, que são matérias-primas, trabalho humano, entre outros. Já a produtividade, segundo Pechincha (2010), mede o desempenho econômico de uma organização ou unidade de produção. Dessa forma, entende-se que a produtividade mede a capacidade de produzir com eficiência.

Um indicador de performance considerado por Junior (2012), é a produtividade, definindo como a medida de eficiência econômica, em que os recursos de entrada são transformados em produtos, objetivando otimizar as entradas para maximizar as saídas. Assim, entende-se que os fatores produtivos, como matérias-primas, devem ser utilizados com alta eficiência para aumentar as saídas, que são os produtos.

Para a economia, a produtividade é fundamental e, sobre isso, Samuelson e Nordhaus (2012, p. 103), afirmam que "um conceito central em economia é a produtividade, um termo que indica a razão entre a produção e os fatores produtivos". Assim, observa-se o desempenho da produtividade na economia das organizações.

Atualmente, com a alta competitividade no mercado, há exigências de produtividade para obter lucratividade e rentabilidade, mas Roth (2011), afirma que a organização não deve buscar uma alta produtividade sem a qualidade do produto, o que gera custos de manutenção através do aumento de produção com baixa qualidade. Portanto, para aumentar a produtividade deve-se buscar aumentar a qualidade dos produtos e também possibilitar ganhos em todas as suas operações.

Portanto, a produtividade é a relação entre a produção e os fatores produtivos, objetivando produzir mais e com melhor qualidade, maximizando os fatores de produção para obter um melhor desempenho e eficiência, produzindo com o mínimo de falhas, garantindo uma maior competitividade para a organi- 
zação.

\subsection{Comunicação e produtividade}

A comunicação dentro das organizações se torna uma exigência para garantir a eficiência nos processos e na produtividade. Além de integrar os colaboradores e desenvolver a imagem da empresa, também incentiva os funcionários a produzir com maior qualidade e obter bons resultados para a organização.

Por meio da comunicação interna os colaboradores conhecem seu papel e sua responsabilidade com a empresa. Sobre isso, Lima et al. (2012), destaca que a comunicação é fator para o sucesso das organizações, podendo criar uma força produtiva. Assim, a comunicação está ligada à realização dos objetivos empresariais e à capacidade de produzir mais e melhor.

No entanto, o processo de comunicação nas organizações é falho e há muita distorção entre a mensagem original e a informação que chega ao destino final. Observa-se uma discordância entre o real objetivo da comunicação e o que ocorre na organização, pois a comunicação possui o propósito de tornar uma mensagem comum, porém, ela não é compreendida pelos colaboradores e a comunicação não é efetivada na empresa.

Sobre a comunicação nas organizações, Chiavenato (2003, p. 128), afirma que "o enfoque das relações humanas mostrou que as comunicações dentro das organizações são terrivelmente falhas [...]". Portanto, verifica-se que a comunicação é um grande problema nas empresas, prejudicando seu funcionamento.

Se a mensagem transmitida não é compreendida pelos colaboradores, torna-se um processo de comunicação interna falho, podendo gerar consequências nas tarefas dos funcionários, pois se eles não possuem as informações necessárias às suas atribuições e atividades, a produção e a qualidade diminuirão, além de ocasionar o retrabalho.

A ação de refazer o trabalho, por causa de informações transmitidas inadequadamente para a atividade, gera um custo maior para a organização, além de perda de tempo, recursos e baixa produtividade, pois terá um retrabalho na tarefa, o que não aconteceria se as informações fossem comunicadas corretamente e o colaborador compreendido as mesmas.

A troca de informações na organização é considerada uma atividade administrativa e sobre isso, Chiavenato (2003), afirma que a comunicação tem o propósito de fornecer as informações necessárias para os colaboradores realizarem as suas tarefas e promover a motivação, a cooperação e a satisfação. Se os funcionários não possuem informações, o desempenho em suas atividades e a satisfação com a empresa diminuirá.

A divulgação de informações que não possui um retorno do processo e não se estabelece um vínculo efetivo, gera relacionamentos conflituosos, rotatividade de pessoal, desmotivação e baixa produtividade. Segundo Matos (2014), 
esse é um problema evidente e fácil de ser percebido no cotidiano das empresas. Dessa forma, entende-se que falta interação na comunicação interna das organizações, ocasionando mal-entendidos e informações inadequadas.

Outra situação que ocasiona a má comunicação e a insatisfação dos colaboradores são pessoas do alto escalão que não transmitem as mensagens adequadamente e não se importam em explicar as tarefas, mesmo se os funcionários não a compreenderam, por estarem se comunicando com seus subordinados e não querem perder tempo com quem não entende os comunicados. $\mathrm{E}$, sobre isso, Matos (2014), afirma que líderes que dizem estar abertos à comunicação, se comportam com prepotência, intolerância e arrogância no cotidiano de trabalho. Essa situação pode gerar desavenças e deixar de explicar uma dúvida e pode complicar muito o ambiente organizacional e as tomadas de decisões, levando a empresa à falência.

Os colaboradores que realizam seus trabalhos sem saber qual é o objetivo e o que a empresa espera com isso, além de informações mal transmitidas, tornam-se insatisfeitos. Pois, Matos $(2014$, p. 6), declara que "sem a comunicação, atrapalhamo-nos no pensar, no fazer e no viver [...]". Esse efeito da má comunicação, de acordo com Lima et al. (2012), gera um ambiente impróprio para se trabalhar em equipe, cria um estado de tensão, diminui o clima organizacional e a produtividade. Visto que, funcionários insatisfeitos não terão motivação para aumentar a produção e com qualidade, o que pode ocasionar a rotatividade de pessoal, sendo prejudicial para a produtividade, que, segundo Junior (2012), mede a relação entre a produção e os fatores produtivos, representados também pelo trabalho humano. Portanto, gera a entrada de mais recursos do que de saídas na produção.

O colaborador que não possui as informações necessárias, não executará bem suas tarefas, diminuindo a produtividade e sua satisfação. Pois, de acordo com Chiavenato (2003), os funcionários devem receber informações capazes de suprir suas necessidades, além de conhecer os padrões de seu trabalho, para melhor realização do mesmo e criando um ambiente propício para isso. Caso contrário, os colaboradores e a organização serão prejudicados.

Sobre a falha no processo de comunicação, Carvalho et al. (2015), afirma que ocorre pela falta da cultura do diálogo nas empresas, que é o grande problema que prejudica as organizações, estando ligado ao comportamento das lideranças. Visto que essa cultura está relacionada aos valores da empresa.

Os líderes não estão engajados na cultura do diálogo e, sobre isso, Lopes (2014), diz que os relacionamentos entre as lideranças e as equipes são fracos, há ausência de ouvir o que os funcionários dizem, suas idéias e impressões, sendo certamente o que mais afeta o funcionamento das empresas. Como consequência, ocorre a improdutividade, o não cumprimento de prazos e objetivos e o 
aumento de custos para o retrabalho.

Uma equipe que não recebe as informações adequadas de seu líder ou, se elas forem transmitidas por outros, de acordo com Dancini (2012), sente-se insegura em relação à liderança. Essa situação gera desentendimentos e diminui o desempenho nas tarefas. Além de favorecer a insatisfação e a desintegração da equipe.

A má comunicação causa insegurança nos colaboradores e perda de controle da equipe pelos gestores, pois não há uma integração e o grupo não trabalha por objetivos em comum. Matos (2014, p. 94), afirma que “[...] uma má comunicação, pela insegurança que gera e pela sensação de perda de controle, estimula os estilos de gestão centralizadora e autoritária [...]", o que se estende em relações conflituosas, individualismo e disputas.

$\mathrm{O}$ individualismo e a centralização das informações tornam o ambiente de trabalho tenso. Os colaboradores não executam com eficiência suas funções, dificultando a tomada de decisão e induzindo ao erro, por conta das informações mal disseminadas ou nem transmitidas. Essas questões incidem diretamente na produtividade da organização.

A falha na comunicação gera insatisfação e induz ao erro nas atividades desempenhadas pelos colaboradores, podendo levar esse problema ao cliente. Visto que os funcionários não possuem uma abertura para o diálogo e não cooperam para obter os melhores resultados. Um exemplo que retrata a falha na comunicação pode ser visto na Figura 2.

Figura 2: Falha na comunicação em um projeto de software 

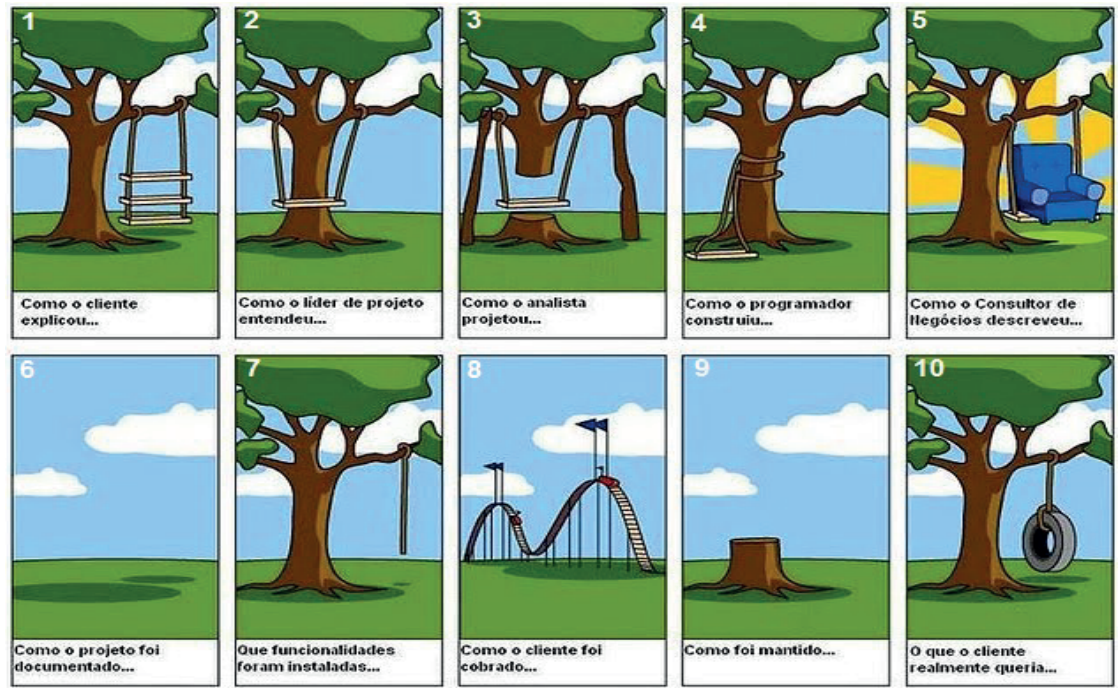

Fonte: Adaptado do Blog Coach on line de Marcos Guilherme (2010). 
Essa figura representa um projeto de software sem sucesso por causa da falha de comunicação, levando esse problema até o produto final do cliente. $\mathrm{Na}$ figura, é demonstrada a falha existente em todos os setores do desenvolvimento do projeto, a falta de diálogo, a desunião da equipe e a falta de cooperação para a realização do projeto.

Observa-se que a falha na comunicação começa no contato com o cliente, não havendo a correta compreensão pelo líder de projeto (quadros 1 e 2 da figura 2). Como não ocorreu mais contato com o cliente para esclarecer dúvidas sobre suas necessidades, o líder de projeto transmitiu as informações para o analista e, o analista para o programador, cujos não compreenderam e fizeram suas tarefas no projeto de formas inadequadas (quadros 3 e 4 da figura 2). Já o consultor de negócios descreveu o produto de software totalmente diferente do projeto em desenvolvimento (quadro 5 da figura 2).

Outro ponto importante é a documentação do projeto, que representa a comunicação escrita, mas na figura em questão não houve esse registro (quadro 6 da figura 2). A comunicação escrita, como a documentação de projetos, manuais, entre outros é de extrema importância para esclarecer dúvidas e rever pontos importantes, a fim de ter clareza na atividade desenvolvida e obter sucesso no projeto.

Ao término do projeto, foram instaladas as funcionalidades para o cliente (quadro 7 da figura 2), porém não satisfazia as necessidades dele nem possuía qualidade. $\mathrm{O}$ cliente foi cobrado com um preço alto e não obteve suporte da empresa (quadros 8 e 9 da figura 2), como consequência da falha existente em todo o processo.

No último quadro da figura 2 , verifica-se a verdadeira necessidade do cliente, que, por falha de comunicação, a organização não conseguiu desenvolver o projeto adequadamente, instalou um produto de software com problemas e não prestou o suporte necessário ao cliente. Dessa forma, torna-se uma situação insatisfatória para o cliente e também para a equipe de trabalho, além dos custos originados pelos defeitos do projeto.

Essa figura ilustra a falha que ocorre em muitos projetos, por não haver diálogo e integração entre os colaboradores, ocasionando improdutividade, produtos sem qualidade, retrabalhos, custos, frustrações e perda de clientes. Matos (2014), afirma que todas as empresas produzem por meio de fluxos de informação e somente terá produtividade e qualidade se as pessoas e equipes estiverem integradas, cooperando para o alcance dos melhores resultados. Dessa forma, verifica-se que a comunicação e o diálogo proporcionam a integração dos colaboradores e são aliados para obter sucesso nos projetos. 


\subsection{A melhoria no processo de comunicação}

A boa comunicação garante uma maior produtividade, qualidade e resultados para a organização, devendo ser utilizada como uma ferramenta estratégica. Sobre isso, Matos (2014), afirma que as companhias internacionais de sucesso desenvolveram uma comunicação integrada, permanente e sistêmica. Dessa forma, a comunicação age como uma atividade estratégica para o público interno e externo, garantindo uma boa imagem institucional e resultados satisfatórios.

A organização que possui um processo de comunicação de qualidade proporciona um ambiente agradável, com espírito de equipe e obtém um melhor desempenho nas atividades. Um bom processo de comunicação melhora o clima organizacional, cujo resultado é a percepção que os colaboradores possuem da empresa. Diminui o estresse, o estado de tensão e mal-entendidos no ambiente de trabalho, voltando-se ao nível de satisfação e motivação dos colaboradores, o que repercute na produtividade.

Os colaboradores que possuem as informações necessárias sobre os objetivos da empresa, seu papel na organização e para a realização adequada das suas tarefas, tornam-se satisfeitos e mais produtivos, gerando competitividade à organização. Além do conhecimento dos funcionários sobre a missão, a visão e os valores da empresa proporcionar uma maior integração entre os colaboradores e a organização.

No entanto, a boa comunicação já não é fácil com pessoas próximas e, em uma organização torna-se mais difícil pelas relações entre as pessoas serem mais tênues. Porém, a boa comunicação deve ser aberta, implantando a cultura do diálogo e começando pelas lideranças. Chiavenato (2014), diz que a direção da organização deve comunicar para motivar e engajar as pessoas para que realizem as tarefas e alcancem os objetivos. Dessa forma, entende-se que os colaboradores devem estar integrados em torno de objetivos em comum e também trabalhar para o bem comum, a fim de conseguir melhores resultados, sendo o papel dos diretores alcançarem essa integração a partir da comunicação.

Uma boa comunicação, assim como conversas e troca de opiniões podem gerar ideias, soluções, projetos, melhoria de processos e inovações para a organização. Para Lopes (2014), o diálogo é fundamental para a produtividade e competitividade da organização e também para a realização e satisfação dos colaboradores. Assim, cria-se um ambiente equilibrado, onde os funcionários se sintam motivados em fazer parte da empresa, dialogando suas ideias e desempenhando suas tarefas para obter resultados.

Para implantar a cultura do diálogo na organização e melhorar o processo de comunicação interna, deve ser desenvolvidos programas para esse fim, mas também, segundo Lopes (2014), os líderes devem estar determinados a isso, 
sendo exemplos e possuindo a atitude de comunicação, pois são os formadores de opinião. Se os líderes estão engajados nesse processo, podem contar com o apoio de todos os funcionários para promover a cultura do diálogo.

Como o primeiro passo para a melhoria do processo de comunicação deve partir da diretoria da organização, deve-se traçar estratégias para elevar a competência dos gestores no âmbito das relações interpessoais.

Um programa de aprendizagem e desenvolvimento pessoal e profissional para a melhoria de competências ou para adquirir novas é o coaching. Uma palavra em inglês que significa treinamento, e que está sendo cada vez mais difundida nas organizações e no mercado. Segundo Lotz e Gramms (2014), o coaching é um processo que faz a pessoa refletir para aumentar seu desempenho e aprendizado em uma determinada área. Esse processo envolve o coach, que é o treinador ou instrutor e é aquele que detém as metodologias e ferramentas utilizadas para o desenvolvimento do coachee, que é o cliente, e que está passando pelo processo de coaching. Esse processo ocorre por meio do diálogo e faz o coachee observar sua situação por outro ponto de vista, abrindo possibilidades para a escolha de novos comportamentos, favorecendo a aprendizagem e o alcance de diferentes resultados.

O coaching pode ser utilizado como estratégia para a superação dos problemas na comunicação, que, de acordo com Cremonezi et al. (2013), é um processo que potencializa o máximo o desempenho dos indivíduos. Se realizado corretamente, pode modificar hábitos na comunicação, na gestão das organizações e das pessoas.

O processo de coaching pode ser aplicado na organização como um programa para o desenvolvimento de novas competências. Para Lotz e Gramms (2014), o coaching nas empresas possui o propósito de instigar a aprendizagem, integrando o autoconhecimento e as habilidades interpessoais às capacidades técnicas e conceituais das pessoas. Dessa forma, os gestores podem desenvolver e aumentar suas competências de comunicação, voltadas para a melhoria no processo interno, assim como para suas próprias habilidades pessoais.

Com as lideranças engajadas nesse processo, também se deve influenciar os colaboradores para a abertura do diálogo. Segundo Lopes (2014), a transparência, a honestidade e a ética na organização são valores necessários para a abertura da comunicação. Por meio dessas atitudes desenvolvidas pelos líderes, sejam por programas como coaching, devem refletir para que haja diálogos e criem vínculos para comportamentos positivos, proativos e que integrem os colaboradores para originar ideias rentáveis para a empresa ou superar uma crise.

Como atitudes para um bom processo de comunicação, Chiavenato (2003), diz que os gestores devem garantir a participação dos colaboradores de escalões inferiores em soluções de problemas na organização e estimular a fran- 
queza e a confiança entre as pessoas. Dessa forma, garante uma maior união entre os colaboradores e a empresa, além da melhoria nas tomadas de decisão.

O desenvolvimento de uma boa comunicação e a integração dos colaboradores provém do envolvimento dos gestores para consolidarem essa cultura e entenderem que todos possuem um papel para o sucesso da organização. Dessa forma, Lima et al. (2012), concorda que a comunicação clara cria melhoria no fluxo de informações e garante resultados satisfatórios na produtividade, contando com o apoio dos gestores e dos colaboradores. Assim, o recebimento das informações de maneira correta diminui as frustrações e influência para obter bons resultados.

Para a comunicação obter sucesso, além de ouvir o que os colaboradores têm a dizer, mostrar interesse e também ser ouvido, Dancini (2012), afirma que é necessário ser objetiva, comunicando o que é realmente importante, evitando falar de coisas periféricas; clara, para proporcionar entendimento e resultado; e precisa, demonstrando todas as informações importantes, como prazos. Se a comunicação atingir o entendimento pelos demais, os resultados consequentemente serão satisfatórios para a produtividade e para toda a organização.

\section{CONSIDERAÇÕES FINAIS}

Nas organizações, a comunicação é vista como um problema que afeta seu funcionamento, principalmente a produtividade. Partindo do estudo sobre os principais conceitos de comunicação, produtividade e processo de comunicação interna, é possível entender o que a comunicação acarreta para a produtividade e como a influência.

De acordo com os dados obtidos na pesquisa, verifica-se que as organizações possuem dificuldades em comunicar, o que gera a falta de integração dos colaboradores, insatisfação, improdutividade, falta de qualidade nos produtos, falha nas tomadas de decisão e rotatividade de pessoal. Esse problema provém da falta da cultura do diálogo nas organizações e dos gestores que não estão engajados nesse processo, que somente dão ordens e não escutam o que os colaboradores têm a dizer.

Sem uma abertura para a comunicação e com o processo de comunicação interna falho, os colaboradores não possuem as informações essenciais para realizar de forma produtiva suas tarefas, não sabem sobre seu papel para o sucesso da organização e nem conhecem os objetivos da mesma. Dessa forma, torna-se um ambiente de trabalho insatisfatório, sem espírito de equipe, com transtornos, por causa de informações mal transmitidas e com produção sem qualidade.

A comunicação influencia na produtividade da organização de forma que, sem as informações necessárias para os colaboradores realizarem suas ati- 
vidades, os mesmos não desempenharão bem suas tarefas, diminuindo a produtividade e a qualidade, ao mesmo tempo em que diminuirá a satisfação de toda a equipe.

Além disso, a comunicação é fundamental para as relações sociais e para o trabalho. A má comunicação faz com que as tensões no ambiente de trabalho aumentem, o colaborador se sente insatisfeito e não consegue executar bem suas tarefas, por conta de informações inadequadas. O quadro de insatisfação gera a rotatividade de pessoal, o que causa mais custos para a empresa, como treinamento de novos colaboradores, afetando diretamente a produtividade, onde há mais entrada de recursos do que de saídas na produção.

Visto que, um bom processo de comunicação interna engaja os colaboradores, produz uma força produtiva, motiva-os a expressar ideias e opiniões para a melhoria da empresa, gera satisfação e promove um trabalho que garanta os melhores resultados. Deve-se ter o engajamento primeiramente das lideranças da empresa e também o desenvolvimento de programas para a melhoria da comunicação interna, como o coaching, que permite a maximização da habilidade de se comunicar, a fim de obter benefícios para o processo de comunicação na organização.

\section{REFERÊNCIAS}

ASSOCIAÇÃO BRASILEIRA DE COMUNICAÇÃO EMPRESARIAL. 4 ${ }^{a}$ Pesquisa comunicação interna 2012. São Paulo, 2012. Disponível em: http:// www.aberje.siteprofissional.com/pesquisa/PesquisaComunicacaoInterna2012. pdf. Acesso em: 03 abr. 2018.

BAUER, M. W.; GASKELL, G. Pesquisa qualitativa com texto, imagem e som: um manual prático. 2. ed. Petrópolis: Vozes, 2002.

BAHIA, B. J. Introdução à comunicação empresarial. Rio de Janeiro: Mauad, 1995.

CARVALHO, C. S. et al. A comunicação interna como meio de atingir a eficácia e eficiência na produtividade empresarial. Revista Científica da Faculdade de Atenas, Paracatu, v. 5, n. 5, 2015. Disponível em: http://www.atenas.edu.br/ Faculdade/conteudo.asp? cat=iniciacaociencia\&id=1240\&pag=layout2. Acesso em: 02 fev. 2018.

CHIAVENATO, I. Introdução à teoria geral da administração: uma visão abrangente da moderna administração das organizações. 7. ed. Rio de Janeiro: 
Elsevier, 2003.

. Administração de recursos humanos: fundamentos básicos. 7. ed. Barueri: Manole, 2009.

- Administração nos novos tempos: os novos horizontes em administração. 3. ed. Barueri: Manole, 2014.

CREMONEZI, G. O. G. et al. Coaching e mentoring como instrumento de foco no cliente interno: um estudo regional em São Paulo. ReFAE - Revista da Faculdade de Administração e Economia, São Paulo, v. 5, n. 1, pp. 166-189, 2013.

DANCINI, W. Sucesso em dose dupla: empreendedores e colaboradores podem chegar juntos ao topo: uma ferramenta indispensável para empresários, líderes e profissionais emergentes. Tatuí: Casa Publicadora Brasileira, 2012.

GIL, A. C. Métodos e técnicas de pesquisa social. 6. ed. São Paulo: Atlas, 2008.

COSTA JUNIOR, E. L. Gestão em processos produtivos. Curitiba: Intersaberes, 2012.

LIMA, S. R. A. et al. A influência da comunicação interna na produtividade. Revista Inova Ação, Teresina, v. 1, n. 2, p. 18-29, jul./dez. 2012.

LOPES, B. (Org.). Comunicação empresarial: transformações e tendências. Rio de Janeiro: Mauad X, 2014.

LOTZ, E. G.; GRAMMS, L. C. Coaching e mentoring. Curitiba: Intersaberes, 2014.

MATOS, G. G. Comunicação empresarial sem complicação: como facilitar a comunicação na empresa, pela via da cultura e do diálogo. 3. ed. Barueri: Manole, 2014.

PECHINCHA, A. C. C. Cultura organizacional: influência na produtividade. 2010. 154 f. Dissertação (Mestrado) - Universidade Lusófona de Humanidades e Tecnologias, Lisboa, 2010.

PRODANOV, C. C.; FREITAS, E. C. Metodologia do trabalho científico: métodos e técnicas da pesquisa e do trabalho acadêmico. 2. ed. Novo Hamburgo: 
Feevale, 2013.

ROSA, A. S.; LANDIM, D. C. B. Comunicação: a ferramenta do profissional. Perquirere: Revista do Núcleo Interdisciplinar de Pesquisa e Extensão do UNIPAM, Patos de Minas, v. 6, n. 6, pp. 141-155, out. 2009.

ROTH, C. W. Qualidade e produtividade. 3. ed. Santa Maria: Colégio Técnico Industrial de Santa Maria, 2011.

SAMUELSON, P. A.; NORDHAUS, W. D. Economia. 19. ed. Porto Alegre: Amgh, 2012.

STEPANSKI, I.; COSTA, M. E. Aspectos comportamentais da gestão de pessoas. Curitiba: Iesde, 2012.

WEIL, P.; TOMPAKOW, R. O corpo fala: a linguagem silenciosa da comunicação não verbal. 69. ed. Petrópolis: Vozes, 1986.

ZIMERMAN, D. E. Fundamentos básicos das grupoterapias. Porto Alegre: Artes Médicas, 1993. 